\title{
CORPOS DAS MARGENS E OUTRAS PEDAGOGIAS POSSÍVEIS
}

Edson Mendes da Silva Júnior ${ }^{\mathrm{i}}$ Fernando Seffner ${ }^{\text {ii }}$

\begin{abstract}
Resumo: O objetivo deste texto é propor a possiblidade de pensarmos a sala de aula como local de produção de pedagogias, por meio de impressões e acontecimentos coletados na etnografia de cenas da cultura escolar. Desse modo, a partir de situações que envolvem a deficiência e os corpos ditos deficientes, discute-se sobre cultura escolar, currículo, escola, culturas juvenis, corpo e desejo. Outrossim, traça-se um histórico da emergência e do percurso da categoria da deficiência, especialmente articulada com os chamados modelo médico e modelo social, assim como avalia-se as principais políticas públicas que articulam o campo da educação com a deficiência. Nesse sentido, conclui-se com a análise de uma cena escolar que sintetiza a referida possibilidade.
\end{abstract}

Palavras-chave: Corporalidades; Deficiência; Modelos de deficiência; Cultura escolar; Educação.

\section{MARGIN'S BODIES AND OTHERS POSSIBILITIES PEDAGOGIES}

Abstract: The objective of this text is to propose the possibility of thinking about the classroom as a place of production of vital pedagogies, through impressions and events collected in the ethnography of school culture scenes. From situations involving disability and so-called disabled bodies, we discuss school culture, curriculum, school, youth cultures, pedagogies, body and desire. A history of the emergency and the route of the disability category is traced, articulated with the so-called medical and social models. The main public policies that articulate the field of education with disability are evaluated, proposing the construction of vital pedagogies. In this sense, it concludes with the analysis of a school scene that synthesizes these possibilities.

Keywords: Corporealities; Disability; Models of disability; School culture; Education.

\section{Da sala de aula, dos corpos e de suas pedagogias}

Uma sala de aula é habitada por corpos. Sem corpos, é apenas uma sala, embora móveis e arquitetura lembrem a função educativa para a qual foi desenhada. Certas visões conservadoras - quando não, autoritárias - em Educação, querem nos fazer crer que há os corpos - de alunos e de alunas, de professores e de professoras ${ }^{\mathrm{iii}}$ - e que, para além deles, existem os conteúdos - as "matérias" - que devem ser ensinados.

Os conteúdos estão materializados nos livros didáticos, nas apostilas, no que se escreve no quadro negro, naquilo que a professora dita eventualmente, no que se copia nos Licença Creative Commons Atribuição Não Comercial-Compartilha Igual (CC BY-NC- 4.0), que permite uso, distribuição e reprodução para fins não comerciais, com a citação dos autores e da fonte original e sob a mesma licença. 


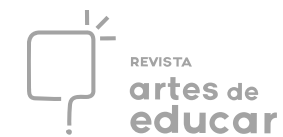

cadernos, e, principalmente, no que se exige em provas e avaliações. São prescritos conteúdos em documentos oficiais, como os guias curriculares ou a Base Nacional Comum Curricular (BNCC - BRASIL, 2020), e naquilo que, por vezes, se chama genericamente de currículo, tomado como lista de tópicos a ensinar. A esses conteúdos, nos últimos anos, se associaram as habilidades e as competências. O contexto político e educacional brasileiro atual, marcado pela emergência de uma racionalidade neoliberal e pelo neoconservadorismo (SEFFNER, 2020), tornou esse modo de pensar a escola seu paradigma. Associou também a valorização da tradição ao processo de seleção do que deve ser ensinado, num movimento que claramente deseja vincular a escola a um retorno ao passado, um passado no qual cada um 'conhecia o seu lugar', no qual se diz que 'havia respeito', onde supostamente 'não havia baderna'.

Neste artigo, queremos investir em outra direção, desenhando, de modo ainda inicial, a noção de caráter vital nas pedagogias, esforço que fazemos fruto de nossos aprendizados na etnografia de cenas escolares, que mostram trajetórias diversas, desejos pulsantes, corpos que importam, aprendizagens que constituem sujeitos e sujeitos que constituem aprendizagens, resistências plurais, desordens criativas, conexões que deixam a norma inquieta, dentre outros movimentos que se dão a partir das margens.

Reescrevendo o que foi dito em parágrafo anterior, começamos por afirmar que uma sala de aula é produzida por corpos. Sem corpos, ela não existe. Não há corpos sem conteúdos, e não há conteúdo sem interação com corpos. O movimento não flui do conteúdo para os corpos. Há movimentos em todas as direções, e há muito mais do que corpos e conteúdos na sala de aula.

Tradições são importantes, mas sem esquecer que constituem artefatos históricos inventados com intencionalidades políticas a serviço de grupos sociais específicos (HOBSBAWM, 1984). Definir e propor currículo é atividade necessária, mas sem esquecer que o currículo é um campo de disputas (ARROYO, 2011). Tais disputas não envolvem apenas a legitimidade de tal ou qual conteúdo, ou desta ou daquela perspectiva teórica. Para os propósitos deste artigo, focamos em uma disputa que anima e dá vitalidade ao currículo, é aquela que se estabelece entre professoras e professores versus alunos e alunas, e que identificamos em nossos esforços de etnografia de cenas escolares. Não é uma disputa entre quem ensina e quem aprende, mas uma disputa entre corpos que portam experiências sociais e trajetórias culturais diversas, e cujo reconhecimento é fundamental para o diálogo das aprendizagens.

Habilidades e competências são duas palavras muito pobres para pensar a riqueza das aprendizagens possíveis em uma sala de aula e, no mais das vezes, capturadas por discurso Revista Interinstitucional Artes de Educar. Rio de Janeiro, V. 7, N. 1 - pág. 232-253 janeiroabril de 2021: "Pedagogias Vitais: Corpo, Desejo e Educação" DOI: 10.12957/ riae.2021.54870 


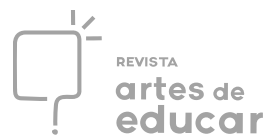

que atrela a formação escolar à preparação para o mercado de trabalho, conforme já de muito tempo se discute na literatura educacional (GENTILI; SILVA, 1995), e num debate atualizado por novas pesquisas (LAVAL, 2004).

Nosso esforço em pensar corpos e em desenhar os contornos do que estamos, ainda de modo provisório, denominando de caráter vital nas pedagogias na cultura escolar, nos faz necessitar de uma definição mais precisa das estratégias que cercam a produção curricular. Seguindo de perto as proposições de Arroyo (2011), e analisando as demandas dos movimentos sociais em gênero e sexualidade acerca da escola e dos processos de escolarização, conforme discutido em SEFFNER \& MOURA (2019), salientamos duas características importantes.

A primeira delas é que os currículos, particularmente das escolas públicas, foram objeto de pressões de movimentos sociais, que resultaram na inclusão de narrativas envolvendo corpos marcados por raça, gênero, sexualidade, geração, religião, classe social, deficiência, região. O sujeito universal que desde sempre predominou nas narrativas curriculares - branco, masculino, heterossexual, de classe média alta, do sul ou sudeste do Brasil, católico, monogâmico - foi um tanto deslocado pela inclusão de outras narrativas. Essas novas narrativas dizem de outros corpos, organizados em movimentos identitários que, de modo saudável e ampliando nossa densidade democrática, quiseram se ver representados nos currículos e, em parte, conseguiram seu intento.

A segunda característica importante para pensar a produção curricular, nesses anos pós-Constituição Federal de 1988 (BRASIL, 1988) e de ampliação das liberdades democráticas entre nós, é que as chamadas minorias não buscaram apenas uma vaga na escola, acreditando que, desse modo, quase que automaticamente, conseguiriam atingir patamares mais elevados de inclusão e cidadania. A cultura escolar se viu no centro de um complexo processo de disputas políticas em que se desejava, com mesmo empenho, obter uma vaga, inserir conteúdos próprios de suas identidades nos programas escolares, articular o percurso escolar com a conquista de outros direitos sociais. A luta por inclusão social incorporou a escola pública na luta maior pelo reconhecimento, pelo acesso aos bens materiais e políticas públicas de inclusão, bem como reconhecimento de marcas culturais, simbólicas e de lugares de memória dessas populações.

Parte significativa dessas demandas sociais ficou evidente nos movimentos de ocupação de escolas, acontecidos entre 2015 e 2016 em diversos estados do Brasil, conforme se analisa em SEFFNER (2017) e se mostra de modo vigoroso no documentário visual intitulado Lute como uma menina, que aborda as ocupações no Estado de São Paulo ${ }^{\text {iv }}$. A Revista Interinstitucional Artes de Educar. Rio de Janeiro, V. 7, N. 1 - pág. 232-253 janeiroabril de 2021: "Pedagogias Vitais: Corpo, Desejo e Educação" DOI: 10.12957/riae.2021.54870 
escola pública é percebida no contemporâneo, por muitos e diferentes movimentos sociais, como uma possível aliada na luta maior pela inclusão social. Esse processo de politização da cultura escolar explica a reação conservadora, expressa particularmente no movimento "ideologia de gênero" e no movimento "escola sem partido", que buscam cercear a todo custo esse processo $^{\mathrm{v}}$.

Ainda sobre a noção de currículo que dialoga com o que desejamos propor e ajuda a pensar no caráter vital em pedagogias, valemo-nos das reflexões postas em Silva (2010), em especial três provocações: entender o que pode ser o currículo em diálogo com práticas de significação, inserido na chamada crise da representação e pensado em articulação com a noção de fetiche.

As três provocações são úteis para os fins que temos neste artigo. Propomos que cada professor e professora assumam que o currículo que executam não é algo que 'apresenta' o mundo 'tal como ele é', mas que de modo afirmativo constrói significações sobre ele, e que essas significações estão em disputa política. Para tanto, sugerimos utilizar a bagagem cultural, não só da classe de alunos e alunas, mas dos próprios docentes, e se indagar a todo momento sobre o que aquilo que está sendo ensinado pode significar, para cada um, a partir do seu lugar.

Em sintonia com o que afirmamos, as narrativas dos diferentes sujeitos na sala de aula podem levar a um debate produtivo sobre o que significa, por exemplo, a noção de corpo da Grécia Antiga, vinculada a um conjunto de práticas corporais, naquele coletivo ali reunido, situado em um tempo e em um espaço determinados. O currículo também pode ser pensado como inserido no interior da chamada crise de representação, provocação que dialoga de perto com o que já discutimos acerca da pressão dos movimentos identitários pela inclusão das narrativas que lhes são próprias no interior do currículo escolar, e que desloca as representações dominantes.

Por fim, tomando alguns elementos da história do termo fetiche, pensamos um currículo que se abra à convivência com ambiguidades, contradições, indeterminações, duplos sentidos, controvérsias, conflitos e disputas. Essas características precisam habitar todos os tipos de conhecimento ensinado, inclusive, aqueles oriundos da ciência. Que se possa desconfiar sempre, e exercer o benefício da dúvida, fazendo disso um exercício de prazer argumentativo.

Nossa atenção especial neste artigo é para com os corpos, e para com a possibilidade de, em parceria com eles, produzir pedagogias animadas pelos desejos - desejo de aprender, de saber de si e dos outros, de ir além, de se mover, de contestar, negociar e conviver. Revista Interinstitucional Artes de Educar. Rio de Janeiro, V. 7, N. 1 - pág. 232-253 janeiroabril de 2021: "Pedagogias Vitais: Corpo, Desejo e Educação" DOI: 10.12957/riae.2021.54870 
Atenção maior temos aqui com os corpos ditos das margens, que portam atributos que podem produzir vergonha, abjeção, estigma, discriminação.

Esse ambiente educacional que dá atenção aos corpos permite atribuir um caráter vital nas pedagogias, tomando em conta as interpelações e relações entre os corpos. Pensamos a palavra corpo no plural, corpos, e para muito além dos plurais. Corpos podem ser coletivos. Há corpos materiais e há corpos virtuais. Há o corpo com que nascemos e há o corpo-comoprojeto, que desejamos e buscamos. Há corpos medicalizados. Corpos considerados úteis ou menos úteis. Corpos racializados, pardos, negros, amarelos, brancos, não brancos, indígenas. Corpos gendrados masculinos, femininos e o que mais se desejar ser em termos de gênero, inclusive gênero neutro. Corpos, corpas, corpes. Há corpos sexualizados, numa profusão que vai muito além das tradicionais três alternativas: heterossexuais, homossexuais, bissexuais. Há corpos que hoje se assumem não binários, pansexuais, poliamorosos, intersex, travestis e transexuais, assexuais, queer etc. Há corpos orientais e ocidentais. Há corpos empoderados, contidos, controlados, controladores, assujeitados e assujeitadores. Há corpos cirurgiados, siliconados, hormonizados, com próteses, cyborg, voláteis, duros, moles. Há corpos marombados. Corpos gordos, magros, anoréxicos. Corpos que vigiam e corpos que são vigiados. Corpos jovens e velhos, adultos e crianças. Corpos que se agitam, corpos calmos. No meio dessa lista, por si só interminável, há aqueles corpos que se acreditam normais, são os que ocupam o centro, e há corpos das margens.

Os movimentos de disputa entre posições de centro e posições das margens não permitem que tenhamos corpos com posição definitiva. Proliferar corpos e possibilidades dos corpos e, em seguida, fazer proliferar relações entre esses corpos é o movimento que permite atribuir a uma pedagogia um caráter vital. Damos especial atenção aos corpos marcados pela deficiência, e é destes que nos ocuparemos centralmente nas reflexões a seguir.

Cabe ressaltar, entretanto, que ainda há outras possibilidades de pensar o corpo no território escolar. Numa sala de aula há todo um linguajar que utiliza o corpo para melhor expressar ideias, sensações, medos, projetos. Isso aparece em cenas do cotidiano escolar em falas como 'trabalho feito nas coxas', 'frio na barriga na hora da prova', 'dedo duro foi falar com a professora', 'as paredes dessa sala têm ouvidos', 'fulana é boca suja', 'a professora disse que ele é cabeça-dura', 'ela falou que é cabeça feita', 'ele chegou na maior cara de pau', 'eu não dou ouvidos a ele', 'e vocês vão ficar aí de braços cruzados?', 'a professora reclamou para a turma que o que ela explica entra por um ouvido e sai pelo outro', 'aquele guri é um mão de vaca', 'ele não entra no nosso time porque é pé frio', 'lá vai a quatro olhos', 'tu não toma vergonha na cara', 'esse trabalho não tem pé nem cabeça', 'ela fala pelos cotovelos', Revista Interinstitucional Artes de Educar. Rio de Janeiro, V. 7, N. 1 - pág. 232-253 janeiroabril de 2021: "Pedagogias Vitais: Corpo, Desejo e Educação" DOI: 10.12957/riae.2021.54870 
'ele tá careca de saber', 'sai olho gordo'. Todas essas percepções de corpos e partes de corpos exigem pensar de modo mais detido sobre suas significações. Alinhamo-nos com a proposição de que somos corpo, não apenas temos corpo:

Olho os corpos como possibilidades de expressão de gestualidades, cuja educação atravessa tempos e culturas fazendo pulsar diferentes rituais e simbologias. [...] entendo o corpo como algo que somos e não como algo que temos. Somos. Portanto, não há como falar de corpo sem falar de nós mesmos, de nossa subjetividade, daquilo que somos ou que gostaríamosde ser. Quando digo corpo, estou me referindo não somente à materialidade biológica que nos constitui, mas a nós mesmos. Afinal, somos corpo. (GOELLNER, 2015, p. 4)

Se somos corpo, “cuja educação atravessa tempos e culturas" (GOELLNER, 2015, p. 4), podemos alinhar essa afirmação com as proposições de Andrade \& Costa (2017), que analisam o conceito de pedagogias culturais como um esforço de expansão do significado da pedagogia, que valoriza as qualidades pedagógicas da vida social; reconhece a proliferação de lugares de aprendizagem na sociedade; abarca as dimensões éticas e morais de produção de si; considera as interpelações feitas por artefatos culturais, em especial os artefatos midiáticos, como potentes na produção de posições de sujeitos; estabelece conexões entre a cultura escolar e o entorno social; e se ocupa de modo amplo com a educação política entre os modos formais e informais.

Conforme Louro (1999), as pedagogias do gênero e da sexualidade, e as pedagogias do corpo, que aqui nos interessam de perto, constituem um recorte específico das pedagogias culturais, atuantes tanto no interior da cultura escolar, como nos artefatos culturais, como filmes, novelas, redes sociais, revistas, propagandas. Nós mesmos somos a composição a partir da atuação das pedagogias culturais, sempre em ação, sempre em disputa, sempre contingentes. O conjunto de instâncias que atua nessa produção sem fim é enorme: prescrições médicas, elementos arquitetônicos, estilos de moda, ditos da tradição, crenças acerca das possibilidades dos corpos - masculinos, femininos, negros, brancos, jovens, velhos -, recomendações dietéticas, códigos morais, padrões de beleza, verdades da ciência, campanhas de educação física, regras do mundo do trabalho, regimentos escolares, currículos, preocupações com a gestualidade, orientações para a qualidade de vida etc. Como resultado, a cada momento desse aparato discursivo e pedagógico, somos um corpo. Somos também um universo de diferenças, o que nos alinha com o:

[...] pressuposto filosófico de que o ser se diz na diferença e não na identidade. Ou seja, não é a identidade e nem o idêntico que define o ser, não é a semelhança ou a continuidade, mas é justamente a diferença. Para 
Deleuze e Guattari, o ser está sempre se definindo na diferença com relação ao outro; o que se repete não é o que se assemelha, mas sim o que difere. (ALBUQUERQUE JÚNIOR, 2020, p. 149-150)

Tais considerações abrem possibilidades para pensar estratégias pedagógicas, que animam pedagogias que qualificamos como vitais na cultura escolar. Abordamos a seguir elementos para compreensão da história da noção de deficiência e de corpos deficientes, nas implicações entre os discursos da saúde e da educação.

\section{Deficiência: das expressões que a definiam à definição do conceito}

De acordo com Sassaki (2012), ao longo do século XX, a expressão os inválidos, utilizada no sentido de retratar os indivíduos considerados sem valor, deu lugar à expressão $o s$ incapacitados que, amplamente divulgada pela mídia da época, denunciava as deficiências produzidas pelas duas grandes guerras mundiais.

Entre os anos de 1960 e 1980, além da expressão os incapacitados, as expressões os defeituosos; os deficientes e os excepcionais também compunham o rol de compreensão da deficiência. Os defeituosos era expressão utilizada em alusão às pessoas que apresentavam deformidades de ordem física. Já a terminologia os deficientes era aceita e difundida na sociedade de maneira a caracterizar aqueles sujeitos que, mesmo ao apresentarem algum tipo de deficiência, conseguiam desempenhar determinadas funções sem auxílio de outrem como, por exemplo, andar e tomar banho. Por seu turno, o termo excepcionais era utilizado, inicialmente, para caracterizar as pessoas com deficiência mental. No contexto brasileiro, a expressão se institucionalizou, a partir da promulgação da Lei de Diretrizes e Base da Educação Nacional (LDBEN) em 1961 (BRASIL, 1961), passando a abarcar, conceitualmente, qualquer tipo de deficiência. Entretanto, com o decorrer dos anos, mais precisamente no início da década de 1980, aquele termo passou a ser reclamado pelos movimentos em prol dos direitos das pessoas superdotadas, que justificavam que os indivíduos com altas habilidades também eram excepcionais, pois se encontravam, conforme pondera Sassaki (2012), na outra extremidade da inteligência humana. O que se viu foi a emergência de um grupo que, com o intento de se reafirmar como sujeito fora do espectro da deficiência, buscou na legislação a garantia e a defesa de seus próprios direitos.

Com o objetivo de organizar uma terminologia universal acerca das diferentes tipologias de deficiência, a Organização Mundial da Saúde (OMS) lançou, em 1980, a 
Classificação Internacional de Impedimentos, Deficiências e Incapacidades (CIDID, OMS, 1980). Por meio dela, buscou-se a discussão dos conceitos de deficiência, desvantagem e incapacidade. Contudo, segundo Chateau (2012), o sistema alvitrado pela CIDID não trazia consigo uma proposta de descolamento da concepção de deficiência da ideia de doença; antes disso, ele concebia a diversidade corporal como o resultado da relação de causalidade entre as perdas e as anormalidades decorrentes de enfermidades.

Após criar, em 1981, o Ano Internacional das Pessoas Deficientes e, consequentemente, inaugurar uma nova terminologia - pessoas deficientes -, em 1982, em Assembleia Geral, a Organização das Nações Unidas (ONU) lançou o Programa de Ação Mundial para as Pessoas Deficientes (ONU, 1982). Ficou definido, dentre outras coisas, que o referido Programa se destinava à realização dos objetivos de igualdade e de participação plena das pessoas deficientes na vida social e no desenvolvimento. Todavia, conquanto houvesse naquele documento a explícita defesa da pessoa com deficiência como um cidadão de direitos, em termos conceituais, o Programa não avançou no sentido de propor um novo olhar sobre a deficiência.

Em 1988, os movimentos em defesa das pessoas com deficiência rechaçaram o termo pessoa deficiente. Alegavam que essa expressão definia o sujeito como um ser deficiente em todos os aspectos e dimensões da vida. Tal reivindicação reverberou em sua transposição para portadores de deficiência, ou seja, tomou-se a deficiência como um valor ou um detalhe inerente a cada pessoa, em uma nova relação corporal. No Brasil, esse novo termo passou a compor o texto da Constituição Federal de 1988 e das políticas pertinentes às diferentes áreas de atuação do governo. A expressão também foi adotada como parte dos nomes formais de Conselhos, associações e coordenadorias, sendo mantidos, em alguns casos, até a atualidade.

A partir da década de 1990, o termo portadores de deficiência começou a ser contestado. Os argumentos giravam em torno da compreensão de que uma pessoa não porta uma deficiência como se fosse algo que a qualquer momento se pudesse abandonar. Portanto, a deficiência começou a ser vista como uma característica que existia para além do querer de qualquer indivíduo e lhe impunha marcas que, em muitos casos, incidiam precisamente na sua constituição como sujeito de direito.

Admitida como uma parte intrínseca à pessoa, a deficiência passou a assumir as expressões pessoa com deficiência ${ }^{v i}$ e necessidades especiais ${ }^{v i i}$, que, após a promulgação da Declaração de Salamanca, em 1994 (BRASIL, 1994b), obteve uma expressiva adesão no âmbito político, no meio social e educacional; no campo da saúde; no contexto das produções e das pesquisas acadêmicas. No que tange, especificamente, à educação, Chateau et al. (2012) 


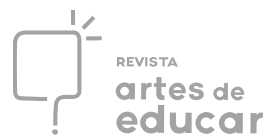

afirmam que a expressão necessidades educativas especiais foi adotada com o intuito de diluir ou atenuar a influência negativa que as outras expressões infringiram ao alunado da educação especial. No mesmo sentido, Mazzotta (1996) reitera que a esse novo termo foi litigada à acepção de característica temporária ou definitiva que, independentemente da deficiência, poder-se-á manifestar em qualquer sujeito.

Até o ano de 2001, pelo menos em termos teóricos, a compreensão sobre deficiência ainda era perpassada fortemente por questões biológicas. Em 2002, a partir da publicação da Classificação Internacional de Funcionalidade, Incapacidade e Saúde (CIF), propõe-se um novo debate sobre a deficiência, e essa passa a ser pensada sob o prisma biopsicossocial. Buscou-se o desenvolvimento de avaliações nas quais evitou-se associar a deficiência às “condições de saúde ou doença", pautando prioritariamente a sua análise na contextualização da pessoa como um ser social atravessado por questões econômicas, culturais, biológicas e orgânicas (CHATEAU et al., 2012, p. 66).

Entre o final do século XX e início do século XXI, o debate acerca da inclusão e integração das pessoas com deficiência na sociedade se intensificou, dando origem ao movimento denominado Nothing About Us Without Us! ${ }^{\text {viii }}$. Em 2006, como resultado de um processo construído por meio da participação efetiva daqueles sujeitos, a ONU lançou, em âmbito global, a Convenção sobre os Direitos das Pessoas com Deficiência ${ }^{\text {ix }}$. Nesse documento, foi explicitado que a deficiência, antes entendida como um termo ou uma expressão, passava a constituir-se como um conceito, o que significou assumir a deficiência não apenas como uma condição pessoal, acentuada por critérios funcionais, mas também como um fenômeno social em constante evolução (BRASIL, 2008).

Em suma, segundo Montanari (2013) e Devandas (2006), o grande avanço empreendido pela Convenção foi a substituição do modelo médico pelo modelo social de deficiência. Isso provocou o deslocamento da acepção de deficiência como um limitador do indivíduo para a compreensão de que é o meio no qual ele se insere que tolhe suas possibilidades de inclusão e acesso a bens e serviços.

A Convenção reconhece a existência de inúmeras formas de deficiência e sinaliza que as pessoas não devem ser tratadas de maneira padronizada e uniforme. Seus postulados sustentam a perspectiva de equiparação de oportunidades, atribuindo à sociedade a responsabilidade pelo acolhimento das diferenças, bem como pela promoção dos meios imprescindíveis à participação das pessoas com deficiência nos distintos setores da sociedade e em condições de igualdade. É com essa perspectiva que nos alinhamos, para pensar uma 
sala de aula em que efetivamente se aprenda com as diferenças, sem reduzir o outro a uma cópia imperfeita de si mesmo.

\section{Pessoas com deficiência, Educação Especial e políticas públicas de educação}

A partir da década de 1990, vislumbrou-se mudança considerável na política educacional brasileira, resultando em novas perspectivas para a Educação Especial. Além dos referenciais normativos publicados no Brasil, houve a realização de conferências e declarações ${ }^{\mathrm{x}}$ que, em âmbito internacional, marcaram a década e influenciaram a formulação de políticas públicas orientadas à educação inclusiva em nosso país (MENDES JÚNIOR; TOSTA, 2012).

Publicada em 1994, a Política Nacional de Educação Especial (BRASIL, 1994a) enfatizava que a Educação Especial era um processo que visava promover o desenvolvimento das potencialidades das pessoas portadoras de deficiência. Destarte, cabia à escola promover uma educação na qual os alunos com deficiência pudessem ter suas possiblidades de aprendizado estimuladas. Tal fato não implicou deslocamento da compreensão de deficiência que, grosso modo, continuou a ser entendida como uma marca que o indivíduo carrega consigo, e não como uma condição humana e social.

Por sua vez, a Lei de Diretrizes e Bases da Educação Nacional (Lei 9.394/1996/ BRASIL, 1996) mudou a configuração do ensino básico e garantiu nova forma de atendimento ao público da Educação Especial - que passou a ser entendida como "modalidade de educação escolar, oferecida preferencialmente na rede regular de ensino, para educandos portadores de necessidades especiais"(BRASIL, 1996, art. 58). Porém, a LDB (BRASIL, 1996) não deslocou a acepção de deficiência para um entendimento mais humanizado daqueles sujeitos. Pelo contrário, apenas explicitou que as necessidades especiais decorriam das dificuldades vinculadas à própria deficiência, bem como daquelas não atribuídas a uma causa orgânica.

Em 1999, o Decreto n $3.298 / 99$ regulamentou a Lei no $7.853 / 89$, dispondo acerca da Política Nacional para Integração da Pessoa Portadora de Deficiência (BRASIL, 1999). Tal decreto previa a oferta da Educação Especial preferencialmente na rede regular de ensino, além de defini-la como modalidade de educação escolar transversal a todos os níveis e modalidades de ensino. Contudo, a matrícula de alunos com deficiência no sistema regular de ensino não lhes assegurava a inclusão em classes comuns. No mesmo sentido, o referido 


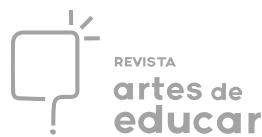

decreto permitia que os espaços especializados assumissem o status de espaço substitutivo da escola - uma vez que, se no entendimento dos profissionais da Educação Especial, a escola regular não conseguisse "satisfazer as necessidades educativas ou sociais do aluno", as escolas especiais e as instituições especializadas possuíam a prerrogativa da matrícula dele (BRASIL, 1999, art. 25).

No período compreendido entre os anos de 2001 e 2014, relevantes mudanças na política educacional brasileira resultaram em novos direcionamentos à Educação Especial, dentre os quais pode-se destacar os movimentos que deram curso à implementação da política de educação inclusiva no país. Acompanhando esse processo, as Diretrizes Nacionais para a Educação Especial na Educação Básica, definidas pela Resolução CNE/CEB no 2/2001 (BRASIL, 2001), determinaram que os sistemas de ensino deveriam matricular todos os alunos e que caberia às escolas se organizarem para o atendimento dos alunos com deficiência, assegurando-lhes "as condições necessárias para uma educação de qualidade" (BRASIL, 2001, art. 2). Essa resolução não fez menção direta ao atendimento educacional especializado, contudo, disse-nos que as escolas da rede regular de ensino deveriam prever e prover na organização de suas classes comuns serviços de apoio pedagógico especializado em salas de recursos.

Ainda em 2001, foi lançado pelo Ministério da Educação (MEC) o Programa Educação Inclusiva: direito à diversidade (BRASIL, 2001), com o objetivo de apoiar a formação de gestores e educadores, bem como difundir a política de inclusão nos municípios brasileiros. O referido Programa buscou prover e dar condições necessárias à garantia do acesso à escolarização, à oferta do atendimento educacional especializado e à promoção da acessibilidade a todos os alunos com deficiência matriculados na rede pública de ensino.

Em 2008, a Política Nacional de Educação Especial na Perspectiva da Educação Inclusiva (PNEEPEI) reafirmava a Educação Especial como modalidade de educação escolar que perpassaria todos os níveis, etapas e modalidades de ensino (BRASIL, 2008). O Atendimento Educacional Especializado (AEE) viria a ser o meio pelo qual se buscaria a complementarização e/ou a suplementação da formação de alunos e alunas e que as atividades realizadas no AEE não seriam "substitutivas à escolarização" daqueles sujeitos, o que também foi reforçado pelo Decreto $n^{\circ} 6.571 / 2008$ e pelo Parecer CNE-CEB no 13/2009. Segundo esses documentos, o atendimento educacional especializado deixaria de existir de forma substitutiva, passando a integrar a proposta pedagógica da escola, além de envolver a participação da família. 
No avanço das emanações legais, o Decreto $n^{\circ}$ 7.611/11, em particular, bem com a revisão da PNEEPEI, em 2020, apresentam alguns pontos de tensão em determinados aspectos de seu texto, dando margem a diversos questionamentos e dúvidas por parte dos segmentos que atuam na Educação Especial neste país. Os pontos críticos que deram origem a tais tensões parecem estar relacionados a situações antes garantidas e conquistadas pela Educação Especial, principalmente no que se refere aos seguintes pontos: à oferta de serviços; ao caráter não substitutivo dessa modalidade de ensino quanto à escolarização; e, mais diretamente, ao financiamento público das instituições privadas e filantrópicas de Educação Especial.

Em síntese, nos 60 últimos anos, foi possível identificar na política educacional brasileira uma considerável sucessão de dispositivos normativos que, principalmente nas duas últimas décadas, possibilitaram a implementação de políticas públicas no sentido de ampliar o acesso à educação e garantir a permanência e as condições de aprendizagem aos alunos com deficiência. Desse modo, antes de assumir os atuais contornos, a Educação Especial no Brasil trilhou um longo caminho, contando com mudanças referentes à concepção de deficiência e, consequentemente, com a emergência de políticas orientadas à garantia da escolarização de pessoas com deficiência em unidades do ensino comum (MENDES JÚNIOR; TOSTA, 2012; SILVA JÚNIOR; BAPTISTA, 2012).

\section{Entre a norma e a falta: modelo médico e modelo social}

Conforme destaca Santos (2010), foi a partir do século XIX que o corpo, nomeadamente deficiente, começou a ser percebido e catalogado como um produto indesejado e patológico do corpo considerado normal. Nessa perspectiva, Mendes Júnior (2018) destaca que a deficiência é, frequentemente, concebida como um fenômeno que se materializa em um corpo que, ao apresentar limitações funcionais, sensoriais e intelectuais, torna-se passível à intervenção médica, portanto, curativa. De acordo com Diniz et al. (2009), esse tipo de abordagem, denominada de modelo médico, ao restringir a análise da deficiência ao corpo, cristaliza ações normalizadoras e responsáveis por situar as pessoas com deficiência no campo da inaptidão, da perda, da falta, da doença e, grosso modo, da reabilitação. Dito isso, Santos (2010) ajuíza que os corpos estão sob à percepção da intervenção, do controle e da cura, em que a deficiência é vista sempre como um problema trágico que - ao acometer 
isoladamente alguns indivíduos menos ditosos -, encontra no tratamento curativo a única resposta social adequada a sua situação.

Todavia, é necessário ressaltar que o corpo saudável surge como uma distinção capaz de ordenar, dentro de certa lógica, aqueles que, sumariamente, são destituídos de beleza e de vigor físico. Nesse sentido, os padrões definidores da normalidade impõem ao corpo com deficiência condições de estética e de atributos desejáveis à felicidade. Há um processo de naturalização a partir do qual o indivíduo com deficiência passa a ver seu próprio corpo de forma negativa. Logo, o corpo não pertence à própria pessoa com deficiência, pois a percepção da sociedade limita-o aos cuidados e às obrigações relativas à deficiência.

Sobre tal aspecto, França (2013) nos diz, de maneira crítica, que o modelo médico de deficiência busca promover a emergência de vidas mais próximas de uma pretensa normalidade padronizada. Assim sendo, Bampi et al. (2010) enfatizam que a deficiência é percebida pela sociedade como um infortúnio ou má sorte pessoal, isto é, como a expressão de limitações relacionadas a aspectos corporais e ao aprendizado do arcabouço de habilidades básicas e necessárias à vida em sociedade. Portanto, afirmam Diniz et al. (2009), a opressão existente sobre o corpo com deficiência é resultante da cultura da normalidade que, por seu turno, é compreendida como "uma expectativa biomédica de padrão de funcionamento da espécie”, bem como um "preceito moral de produtividade e adequação às normas sociais" vigentes (p. 97-98).

De tal proposição, é preciso destacar que muitas concepções negativas acerca da pessoa com deficiência ainda pululam o imaginário coletivo e constituem a maneira como seu corpo é percebido pela sociedade. Isso significa dizer que, ainda que operem com referenciais sociais para pensar a deficiência, as legislações vigentes não promoveram a superação dos estigmas que deram os contornos à compreensão da deficiência. Consequentemente, tais leis corroboram a construção de enunciados que, ao situarem o corpo da pessoa com deficiência como algo desviante, fora dos padrões de normalidade e de beleza, implica-o, necessariamente, às questões relacionadas à saúde.

Em sentido distinto, alinhamo-nos nesse texto com a compreensão teórica que dá corpo ao chamado modelo social de deficiência, que tem sua gênese entre os anos de 1960 e 1970. Produto das discussões e das críticas em torno das limitações do modelo médico, o modelo em tela emerge não somente como uma proposição eminentemente política decorrente dos chamados Social Disability Movement ${ }^{x i}$, , mas também como uma alternativa à semântica, à autoridade e à hegemonia da perspectiva médica sobre a deficiência. A despeito de tal premissa, Mendes Júnior e Seffner (2020) destacam que essa nova abordagem torna Revista Interinstitucional Artes de Educar. Rio de Janeiro, V. 7, N. 1 - pág. 232-253 janeiroabril de 2021: "Pedagogias Vitais: Corpo, Desejo e Educação" DOI: 10.12957/ riae.2021.54870 
patente que o conceito de deficiência somente se operacionaliza quando apreendido como um fenômeno social. Sua manifestação depende ou resulta do tipo de interação estabelecida entre os sujeitos com aquelas características e o contexto que os circunda. No mesmo sentido, Santos (2010) afirma que, originário do campo da Sociologia, o modelo social centrou sua análise no indivíduo e nas relações que o constituem. Assim, o corpo com impedimentos deixou de ser o foco de uma dinâmica causal, meio pelo qual o modelo médico geria a relação deficiência-sociedade, e passou a se materializar na relação estabelecida entre a sociedade e o sujeito com deficiência.

Contrariamente ao modelo médico, a deficiência, no modelo social, deixou de se constituir por meio do contraste com a normalidade. Portanto, concebida como um fenômeno, bem como um processo que não se restringe ao corpo, a deficiência passa a ser reconhecida como um construto social - que, por ora, é definido como mecanismo de produção das incapacidades de natureza física, sensorial, mental ou intelectual (MELLO; NUERNBERG, 2012).

É importante ressaltar que, quando a gênese da deficiência passa a situar-se na sociedade, em decorrência da análise do modelo social, reconhece-se que as pessoas com deficiência são sujeitos de direitos. A desvantagem social, vivenciada por aqueles indivíduos, não é mais uma sentença da natureza, mas o resultado de um movimento discursivo da cultura da normalidade que descreve os impedimentos corporais como abjetos à vida social. $\mathrm{O}$ modelo social retirou as diferenças corporais, sensoriais e intelectuais do âmbito das anomalias e da patologia para ratificar que "existem diferentes formas de funcionamento de um corpo, de tal modo que não se pode predizer a existência de uma norma a todos os seres humanos" (DINIZ et al., 2009, p. 98-108). Isto é, nem toda pessoa com deficiência vive a experiência da deficiência, ou a vive do mesmo modo ou na mesma intensidade.

No campo político, a deficiência passou a ser definida como um produto da exclusão social e econômica. Assim, no modelo social, a deficiência resulta de dinâmicas sociais que não a consideram uma das expressões da diversidade humana, mas sim um problema particular intrínseco à trajetória individual de cada sujeito. No mesmo sentido, reforça-se que o conceito de deficiência, aquele defendido pela Convenção Sobre os Direitos da Pessoa com Deficiência (CDPD) ${ }^{\mathrm{xi}}$, é resultante de um amplo debate, no qual se defende que deficiência é resultante das interações pessoais e socioambientais estabelecidas entre o sujeito com impedimentos e o meio no qual encontra-se imbricado. Defende-se, ainda, conforme analisa Mello e Nuernberg (2012), a premissa de que "as experiências de opressão vivenciadas pelas 
pessoas com deficiência" não residem na lesão ou no corpo lesionado, "mas na estrutura social incapaz de responder à diversidade” e "à variação corporal humana” (p. 638).

Com base no exposto, ressalta-se que o modelo médico ou biomédico de deficiência coexiste e, em muitos casos, complementa o modelo social no sentido de promover ações integradas, destinadas à promoção e à proteção dos direitos das pessoas com deficiência. Entretanto, compreendemos que a norma necessita, com muito vigor, da caracterização do desvio como sua fronteira e limite de possibilidade. Isto é, uma vez que um corpo percebido como desviante, ou abjeto, se traduz no espaço no qual nos pensamos normais, isso nos faz esquecer, ou minimizar, a noção da diversidade humana e da pluralidade de culturas.

Todavia, ao alargarmos o nosso olhar para as pessoas com deficiência, percebemos que o seu corpo, o seu desejo, a sua sexualidade, assim como a sua educabilidade foram e são apreendidas como sinônimo de sua própria deficiência. De fato, entende-se que, ao dissertarmos acerca das questões que envolvem a vida daqueles sujeitos, falamos também acerca das narrativas que enunciam, quase que de forma automática, o que seja um corpo com impedimentos em comparação com aquele corpo descrito como normal. A deficiência é, como traçamos acima, um tema carregado de história, de sentidos e de significados, e, quando dela falamos, estamos também a falar dos mecanismos que definiram a norma, e quem seriam os normais.

\section{Somos todos deficientes: um estudo de caso}

Neste capítulo, por meio de impressões e acontecimentos coletados na etnografia de cenas da cultura escolar, partimos de uma compreensão apoiada no conceito de precariedade, e nas ideias de Butler (2006) acerca das vidas precárias. A chamada Somos todos deficientes, que abre esse último tópico do texto, deseja construir uma sala de aula em que todos estejamos implicados com o tema da deficiência. Fazemos isso, partindo da ideia de que todos somos precários. Não existimos sem a inserção em redes de cuidado e ajuda com outros. Não ocupamos um lugar universal, pois somos seres situados em contextos.

Pensando na distribuição de riqueza e oportunidades do mundo atual, é bem possível que todos nós estejamos situados nas periferias, somos corpos das margens. Somos indivíduos, é claro, mas frequentemente sucumbimos a uma noção prepotente de que somos seres completos, donos absolutos de nossos destinos e de nossos corpos, traçando nossos caminhos individualmente. Queremos pensar aqui que só conseguimos sobreviver por conta 
das alianças; nossa vida só tem chances de sobrevivência se nos pensarmos como corpos em aliança, e afirmamos isso novamente apoiados em Judith Butler (2018). É a presença de nossos corpos em aliança que qualifica o espaço público, e a sala de aula é uma experiência de vida no espaço público. Todas as vidas são valiosas, e devem ser preservadas, porque umas dependem das outras.

Cada um de nós, quando atua, não atua isoladamente. Atuamos para os outros, e com os outros. Quem veio antes de nós construiu boa parte do cenário onde atuamos. Atuamos, dessa forma, inclusive em sintonia com os que nos antecederam. O resultado da nossa atuação vai afetar os que virão depois de nós. A noção de solidariedade é também aqui importante. $\mathrm{O}$ gosto de perceber que há uma comunidade que pode me ajudar, me suportar, me dar apoio para que eu possa ser mais. Somos sempre sociais na atuação, atuamos em sintonia com os demais.

A presença de corpos deficientes gera mais perguntas do que respostas em uma sala de aula. Quem é considerado sujeito e quem não o é? O que isso tem a ver com a viabilidade da própria vida? Essas são perguntas que alimentam o que aqui valorizamos como um caráter vital nas pedagogias, que implicam a própria vida. O título desse item quer acentuar que somos, em primeiro lugar, precários. Superamos essa precariedade com a resistência. Construímos estruturas que nos auxiliam a superar a precariedade. Entretanto, infelizmente, vivemos em um mundo onde, muitas vezes, a estrutura falha, ou só beneficia poucos. Com isso, nossa precariedade tem um acréscimo de vulnerabilidade. Este substantivo diz daquela parcela que podemos evitar, resistir. Os apoios que construímos ampliam nossa vida.

A vida é política e fazer política é lutar pelo reconhecimento. Há demanda por reconhecimento: eu existo se você me reconhecer. O corpo deficiente na sala de aula nos faz pensar nas condições de aprendizagem que ali existem para esses sujeitos e para todos nós. Todos precisamos de apoios técnicos, emocionais, logísticos para nossos corpos. Isso levanta uma questão que só pode ser respondida coletivamente: o que preciso para existir e aprender? É nessa direção que interpretamos um grande conjunto de pequenos acontecimentos que são objeto de nossa pesquisa na etnografia de cenas da cultura escolar, a dar pistas sobre a produção de certo caráter vital nas pedagogias, que produzem aprendizagens de grande impacto nas vidas de todos e de todas. É o que nos foi dado perceber na oportunidade de realizar a etnografia de uma cena escolar, narrada a seguir.

Uma tarde muito agradável de primavera, em escola municipal de um bairro da zona leste de Porto Alegre. Estávamos ali para observar algumas aulas, sentados no fundo da sala ${ }^{x i i}$. A classe de sétimo ano do Ensino Fundamental estava conversando com o professor Revista Interinstitucional Artes de Educar. Rio de Janeiro, V. 7, N. 1 - pág. 232-253 janeiroabril de 2021: "Pedagogias Vitais: Corpo, Desejo e Educação" DOI: 10.12957/riae.2021.54870 


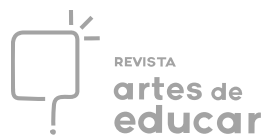

de História acerca da visita que fizeram com ele à Feira do Livro de Porto Alegre, na tarde do dia anterior. A animação era muito grande, com grande vibração no ar. Assistiram a um sarau de poesia em que, ao final, assim de improviso, foram convidados a subir ao estrado e recitar algo que lhes parecesse poético, a partir de palavras dadas também de improviso.

A atividade começou com todo mundo meio constrangido. A sala era enorme, dentro de um centro cultural muito imponente que se localiza no entorno da praça, a plateia muito numerosa, e tudo estava sendo filmado, de modo profissional, com iluminação e técnica. A poetisa era pessoa famosa, estava lançando dois livros na feira. Ela chamava algum dos alunos, indicava as palavras, mas a atividade não ganhava animação no início, todo mundo muito travado, segundo o relato que estava sendo feito pelos alunos e pelas alunas.

João, um menino deficiente que faz parte da turma desde as séries iniciais foi então chamado ao estrado para o exercício poético. As palavras que lhe deram foram ouro e amarelo. De imediato, ele encarou a plateia, assumiu uma atitude de poeta, segundo o relato dos colegas, e referiu que havia ido ao banheiro urinar, e fez uma rima com urina, dourado, alecrim dourado, ouro e batata assada dourada. Explicou que a mãe dele havia cozinhado naquele dia batatas com alecrim dourado, era batata dourada, um prato que ele gostava. Terminou perguntando "urina tem a ver com ouro, né professora?", dirigindo-se à poetisa.

A sala do sarau explodiu em risos e palmas, foi algo contagiante. Romperam-se todos os formalismos, e vários colegas da turma subiram ao palco com ele, e inventaram poesias, $e$ disseram frases engraçadas que já haviam sido ditas na sala de aula. Fez muito sucesso, entre outras, a frase de uma menina da turma, dita durante um debate, que era mais ou menos assim "não é que eu discorde da senhora professora, mas é que eu também não concordo".

A poetisa ficou maravilhada, convidou toda turma ao palco, explicou que aquele riso continha em si a possibilidade de ver as coisas por outro lado, e isso era muito poético. A turma foi chamada pelas pessoas da plateia de uma "turma poética". O professor de História, que havia levado a classe a essa visita na feira, foi também chamado ao estrado, tudo foi fotografado, inclusive pelas pessoas da plateia. O acontecimento causou um impacto enorme na turma, que contou tudo ao restante da escola. As relações entre os alunos e as alunas se estreitaram. De modo surpreendente, uma menina afirmou, em voz alta, que várias vezes, na turma, colegas haviam feito indagações sobre o João, se o João era feliz ou não. E hoje se podia dizer que o João não apenas era feliz, como tinha feito todo mundo feliz. Que se o João não tivesse subido no estrado para fazer poesia, tudo aquilo teria sido muito chato. Houve aplausos e abraços.

Revista Interinstitucional Artes de Educar. Rio de Janeiro, V. 7, N. 1 - pág. 232-253 janeiroabril de 2021: "Pedagogias Vitais: Corpo, Desejo e Educação" DOI: 10.12957/riae.2021.54870 
A educação se dá nas relações. Mais do que corpos em uma sala de aula, temos um regime de corporeidade, em que o que importa são as conexões e dinâmicas dos corpos entre si, mais do que seus atributos particulares. Os elementos materiais que constituem um corpo só tomam sentido na conexão com os demais, com o espaço e com as interpelações. A potência está dada pelas conexões. Perceber desse modo aponta o caminho na direção da valorização do que aqui denominamos de certo caráter vital das pedagogias em sala de aula. Invertendo o raciocínio que aponta que são os seres imperfeitos, deficientes, que precisam dos outros, o episódio mostrou que os outros precisaram do João para brilhar. Isso lembra uma das reflexões postas na obra Emílio, de Rousseau:

Todos os afetos são indícios de insuficiência: se cada um de nós não tivesse necessidade dos outros, nunca pensaria em unir-se a eles [...]. Se algum ser imperfeito se pudesse bastar a si mesmo, de que desfrutaria ele, na nossa opinião? Estaria só, seria miserável. Não posso acreditar que aquele que não precisa de nada possa amar alguma coisa: não acredito que aquele que não ama nada se possa sentir feliz. (ROUSSEAU, 1999, p. 286)

Ao borrar a fronteira dada entre os que eram, supostamente, normais e os outros que eram, supostamente, deficientes, toda a classe de alunos e de alunas teve a oportunidade de existir de outro modo, o que marca a emergência do caráter que estamos denominando de vital, a animar as pedagogias de aprendizagem.

\section{REFERÊNCIAS}

ALBUQUERQUE JÚNIOR, D. M. de. Corpo, acontecimento e diferença: Deleuze e Guattari e a historiografia. História Unisinos, São Leopoldo, v. 24, n. 1, p. 149-156, jan./abr. 2020. Disponível em: http://revistas.unisinos.br/index.php/historia/article/view/hist.2020.241.13. Acesso em: 20 jul. 2020.

ANDRADE, P. D.; COSTA, M. V. Nos rastros do conceito de pedagogias culturais: invenção, disseminação e usos. Educação em Revista. Belo Horizonte, n.33, e157950, 2017 Disponível em: https://www.scielo.br/pdf/edur/v33/1982-6621-edur-33-e157950.pdf. Acesso em: 2 jun. 2020.

ARROYO, M. Currículo, território em disputa. Petrópolis: Vozes, 2011.

AUGUSTIN, I. Modelos de deficiência e suas implicações na educação inclusiva. In.:Anais do IX Seminário de Pesquisa em Educação da Região Sul da Associação Nacional de PósGraduação em Educação (ANPED SUL), 9, 2012. Caxias do Sul: UCS, 2012. 
BAMPI, L. N. S.; GUILHEM, D.; ALVES, E. D.Modelo social: uma nova abordagem para o tema deficiência. Rev. Latino-Am. Enfermagem [online], 2010, v. 18, n. 4, p. 816-823.

ISSN 1518-8345.

BARBOSA-FOHRMANN, A. P. Os modelos médico e social de deficiência a partir dos significados de segregação e inclusão nos discursos de Michel Foucault e de Martha Nussbaum. 2 JournalofInstitutionalStudies, v. 2, n. 2, p. 736-755, 2016.

BRASIL. Ministério da Educação. Base Nacional Comum Curricular. Disponível em: http://basenacionalcomum.mec.gov.br/images/BNCC_EI_EF_110518_versaofinal_site.pdf. Acesso em:13 set. 2020.

. Ministério da Educação. SEESP. Política Nacional de Educação Especial na Perspectiva da Educação Inclusiva. Brasília: MEC, 2008.

Decreto $\mathrm{n}^{\circ}$ 6.094, de 24 de abril de 2007. Dispõe sobre a implementação do Plano de Metas Compromisso Todos pela Educação, pela União Federal, em regime de colaboração com Municípios, Distrito Federal e Estados, e a participação das famílias e da comunidade, mediante programas e ações de assistência técnica e financeira, visando à mobilização social pela melhoria da qualidade da educação básica. Brasília, 2007.

. Ministério da Educação. SEESP. Programa Educação Inclusiva: direito à diversidade. Brasília: MEC, 2001. 138p.

Ministério da Educação. Secretaria de Educação Especial. Decreto no 3.298, de 20 de dezembro de 1999. Brasília: MEC, 1999.

Ministério da Educação. Lei no 9.394, de 20 de dezembro de 1996. Lei de Diretrizes e Bases da Educação Nacional (LDB). Brasília: MEC, 1996.

Ministério da Educação. Secretaria de Educação Especial. Política Nacional de Educação Especial. Brasília: MEC/SEESP, 1994a.

. Ministério da Educação. Declaração de Salamanca. Conferência Mundial sobre Necessidades Educativas Especiais: acesso e qualidade. Salamanca - Espanha (1994). Brasília: MEC, 1994b.

(1988). Constituição da República Federativa do Brasil de 1988. Brasília: Presidência da República, 1988.

Ministério da Educação. Lei de Diretrizes e Bases da Educação Nacional. LDB nº 4.024, de 20 de dezembro de 1961. Brasília: MEC, 1961.

BUTLER, J. Corpos em aliança e a política das ruas. Notas para uma teoria performativa de assembleia. Rio de Janeiro: Civilização Brasileira, 2018.

BUTLER, J. Vida precaria. El poder del duelo y la violencia. Buenos Aires: Paidós, 2006. 
CHATEAU, L. F. A. A associação da expressão necessidades especiais ao conceito de deficiência. Cadernos de Pós-Graduação em Distúrbios do Desenvolvimento, São Paulo, v. 12, n. 1, p. 65-71, 2012.

DEVANDAS, C. Proyecto Sur. Trabalho apresentado na $2^{a}$ Reunião do Proyecto Sur. Nova York, 2006. Não publicado

DINIZ, D.; BARBOSA, L.; SANTOS, W. R.Deficiência, direitos humanos e justiça.Sur, Rev. int. direitos human. [online], v. 6, n. 11, p. 64-77, 2009. ISSN 1806-6445.

FRANÇA, T. H. Modelo social de deficiência: uma ferramenta sociológica para a emancipação social. Revista Lutas Sociais, v. 17, n. 31, p. 59-73, 2013.

GENTILI, P.; SILVA, T. T. da (Orgs.). Neoliberalismo, qualidade total e educação. Visões críticas. Petrópolis: Vozes, 1995.

GOELLNER, S. V. Corpo: (re)pensando entendimentos, articulações e possibilidades. Revista Diversidade e Educação, Rio Grande/RS, v.3, n.5, jan./jun. 2015, p. 4-7 Disponível em:

http://www.educadores.diaadia.pr.gov.br/arquivos/File/pdf/revista_diversidade_educacao_5.p df. Acesso em: 20 jul. 2020.

HOBSBAWM, E. Introdução. In.: HOBSBAWM, E.; RANGER, T. (Orgs.). A invenção das tradições. Rio de Janeiro: Paz e Terra, 1984. P. 9-23.

LAVAL, C. A Escola não é uma empresa. O neoliberalismo em ataque ao ensino público. Londrina: Editora Planta, 2004.

LOURO, G L. Pedagogias da sexualidade. In.: LOURO, G. L. O Corpo

Educado,Pedagogias da Sexualidade. Belo Horizonte: Autêntica, 1999. P. 7-34.

MAZZOTTA, M. J. S. Educação especial no Brasil: história e políticas públicas. São Paulo: Cortez, 1996.

MELLO, A. G.; NUERNBERG, A. H. Gênero e deficiência: interseções e perspectivas. Estudos Feministas, Florianópolis, v. 20, n. 3, p. 384, set./dez. 2012.

MENDES JÚNIOR, E. Entre o fisiológico e o social: modelo médico e modelo social nas pesquisas sobre sexualidade da pessoa com deficiência. 2018. 175 f. Tese (Doutorado em Educação) - Programa de Pós-Graduação em Educação, Faculdade de Educação, Universidade Federal do Rio Grande do Sul, Porto Alegre, 2018.

MENDES JÚNIOR, E. Alunos de escolas especiais: trajetórias na rede municipal de ensino de Porto Alegre. 2013. 150 f. Dissertação (Mestrado em Educação) - Programa de Pós-Graduação em Educação, Faculdade de Educação, Universidade Federal do Rio Grande do Sul, Porto Alegre, 2013.

MENDES JÚNIOR, E.; SEFFNER, Fernando. Conexões entre sexualidade e deficiência são desafios para pensar escola diversa e inclusiva. Revista de Estudos Interdisciplinares, v. 2, p. 86-106, 2020. 
MENDES JÚNIOR, E.; TOSTA, E. I. L. 50 Anos de Políticas de Educação Especial no Brasil: Movimentos, Avanços e Retrocessos. Anais do IX Seminário de Pesquisa em Educação da Região Sul da Associação Nacional de Pós-Graduação em Educação. Caxias do Sul, RS, 2012.

MONTANARI. F. A. O Conceito de Deficiência na Convenção da ONU sobre os Direitos das Pessoas com Deficiência. Revista Reação. Ed. 94. São Paulo, 2013.

ONU. ORGANIZAÇÃO DAS NAÇÕES UNIDAS. Resolução 37/52, de 3 de dezembro de 1982. Estabelece o Programa de Ação Mundial para as Pessoas Deficientes. ONU, 1982.

OMS. ORGANIZAÇÃO MUNDIAL DA SAÚDE.Classificação internacional de impedimentos, deficiências e incapacidades. Genebra: OMS, 1980.

ROUSSEAU, J. J. Emílio: ou da Educação. São Paulo: Martins Fontes, 1999.

SANTOS, W. Assistência social e deficiência no Brasil: o reflexo do debate internacional dos direitos das pessoas com deficiência. Serv. Soc. Rev., Londrina, v. 13, n. 1, p. 80-101, jul./dez. 2010.

SANTOS, W. Deficiência, desigualdade e assistência social: o Brasil e o debate Internacional. In.: DINIZ, D. (Org.). Deficiência e Descriminação. Letras Livres: Brasília, 2010. P. 117-141.

SASSAKI, R. K. Por Falar em Classificação de Deficiências. Revista Brasileira de Tradução Visual, v. 12, n. 12, 2012. Disponível em: https://audiodescriptionworldwide.com/associados-da-inclusao/rbtv/por-falar-emclassificacao-de-deficiencias/.Acesso em: 01 jun. 2016.

SASSAKI, R. K.. Causa, impedimento, deficiência e incapacidade, segundo a inclusão. Revista Reação, São Paulo, ano XIV, n. 87, p. 14-16, jul./ago. 2012.

SEFFNER, F. Sempre atrás de um buraco tem um olho: racionalidade neoliberal, autoritarismo fundamentalista, gênero e sexualidade na Educação Básica. Práxis Educativa (UEPG. ONLINE), v. 15, p. 1-19, 2020. Disponível em:

https://www.revistas2.uepg.br/index.php/praxiseducativa/article/view/15010. Acesso em: 2 jun. 2020.

SEFFNER, F.; MOURA, F. Percurso escolar, pluralismo democrático e marcadores sociais da diferença: necessárias negociações. Linguagens, Educação e Sociedade, Teresina, UFPI, ano 24, n. 41, p. 191-219, jan./abr. 2019. Disponível em:

https://www.ojs.ufpi.br/index.php/lingedusoc/article/view/8747. Acesso em: 20 ago. 2020.

SEFFNER, F. Ocupar é viver a escola. In: CATTANI, Antonio David. (Org.). Escolas Ocupadas. Porto Alegre: Editora CirKula, 2017. P. 13-40.

SILVA, T. T. da. Currículo como fetiche: a poética e a política do texto curricular. Belo Horizonte: Autêntica, 2010. 


\section{SILVA JÚNIOR, E. M.; BAPTISTA, C. R. Trajetórias Construídas em Escolas Especiais: da crença em uma educação inclusiva à transitoriedade restrita. Revista Políticas Educativas, Dossiê Políticas Curriculares, v. 6, n. 1, p. 107-121, 2012.}

WERNECK, C. Modelo médico x modelo social da deficiência. In.:Manual da mídia legal 3: comunicações pela saúde. Escola de Gente - Rio de Janeiro: WVA Editora, 2004. P. 16-20

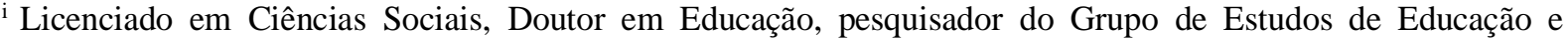
Relações de Gênero GEERGE da UFRGS. Porto Alegre, Brasil. E-mail: edsonmsjr@gmail.com. ORCID: https://orcid.org/0000-0001-9389-2885.

iiLicenciado em História, Doutor em Educação, docente no Programa de Pós-Graduação em Educação PPGEDU e coordenador do Grupo de Estudos de Educação e Relações de Gênero GEERGE da UFRGS. Porto Alegre, Brasil. E-mail: fernandoseffner@gmail.com. ORCID: ttp://orcid.org/0000-0002-4580-6652.
}

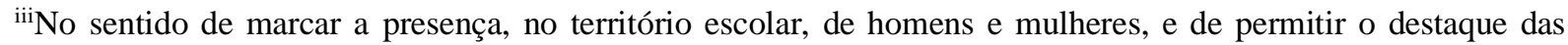
relações de gênero daí decorrentes, ao longo do artigo utilizamos as formas professores e professoras, alunos e alunas, e por vezes apenas a forma no masculino, ou apenas a forma no feminino. Tal estratégia visa lembrar, a cada momento, a importância do marcador gênero na argumentação que construímos.

iv Documentário produzido em 2016, direção de Flávio Colombini e Beatriz Alonso, 1h16min. Disponível em: https://www.youtube.com/watch?v=8OCUMGHm2oA. Acesso em: 20 de agosto de 2020.

" O movimento "ideologia de gênero" é um movimento social de caráter conservador marcado por ações que buscam eliminar do currículo escolar, dos livros didáticos e das políticas públicas em educação temas, questões e aprendizagens envolvendo o marcador social gênero. O movimento "escola sem partido" é tanto uma proposição legislativa quanto um movimento social, igualmente de cunho conservador, que busca estabelecer a precedência dos valores familiares sobre os valores escolares, cerceando com isso a liberdade de ensinar, princípio assegurado na Constituição Federal de 1988.

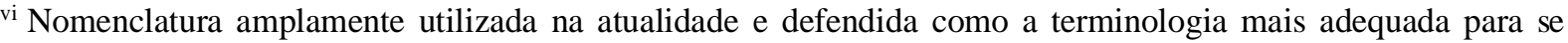
referir à pessoa com deficiência.

vii Origina-se daí as terminologias "pessoas com necessidades especiais"; "pessoas portadoras de necessidades especiais" e seus derivados: "crianças especiais"; "alunos especiais" etc.

viii O termo entrou em uso no ativismo em prol das pessoas com deficiência durante os anos 1990. É um slogan utilizado para anunciar a ideia de que nenhuma política deve ser decidida por qualquer representante sem a participação plena e direta dos membros dos grupos afetados por essa política.

ix Documento ratificado com efeito de emenda constitucional por meio do Decreto Legislativo ${ }^{\circ}$. 186/2008 do Congresso Nacional e promulgado pelo Decreto nº 6.949/2009 da Presidência da República.

${ }^{x}$ Conferência de Educação Mundial para Todos em Jontiem - Tailândia (1990); Conferência Mundial sobre Necessidades Educativas Especiais: acesso e qualidade, que aconteceu em Salamanca - Espanha (1994); e a Convenção Interamericana para a Eliminação de todas as formas de Discriminação contra as Pessoas Portadoras de Deficiência, na Guatemala (1999).

${ }^{x i}$ O Movimento pelos Direitos das Pessoas com Deficiência é um movimento social - de incidência global que atua de maneira a garantir igualdade de oportunidades e direitos iguais para todas as pessoas com deficiência.

xii Aprovada pela Assembleia Geral da Organização das Nações Unidas (ONU), em 2006, e promulgada pelo Brasil em 2007 (Decreto $n^{\circ}$.6.949), a Convenção Sobre os Direitos da Pessoa com Deficiência é o primeiro documento ou tratado internacional do século XXI que trata, especificamente, acerca das pessoas com deficiência no âmbito de proteção jurídica dos direitos humanos da ONU (BARBOSA-FOHRMANN, 2016, p. 739-740).

xiii Etnografia de cenas escolares realizada no âmbito do projeto de pesquisa intitulado Investigação das aprendizagens de estagiários na produção de atividades didáticas e na relação com as culturas juvenis a partir dos relatórios de estágio docente em Ensino de História, financiamento parcial CNPq Processo: 308086/2018-0. 